\title{
Ecology and Epidemiology of Tickborne Pathogens, Washington, USA, 2011-2016
}

Elizabeth A. Dykstra, ${ }^{1}$ Hanna N. Oltean, ${ }^{1}$ David Kangiser, Nicola Marsden-Haug, Stephen M. Rich, Guang Xu, Min-Kuang Lee, Muhammad G. Morshed, Christine B. Graham, Rebecca J. Eisen

\section{Medscape ACTIVITY}

In support of improving patient care, this activity has been planned and implemented by Medscape, LLC and Emerging Infectious Diseases. Medscape, LLC is jointly accredited by the Accreditation Council for Continuing Medical Education (ACCME), the Accreditation Council for Pharmacy Education (ACPE), and the American Nurses Credentialing Center (ANCC), to provide continuing education for the healthcare team.

Medscape, LLC designates this Journal-based CME activity for a maximum of 1.00 AMA PRA Category 1 Credit(s) ${ }^{\mathrm{TM}}$. Physicians should claim only the credit commensurate with the extent of their participation in the activity.

Successful completion of this CME activity, which includes participation in the evaluation component, enables the participant to earn up to $1.0 \mathrm{MOC}$ points in the American Board of Internal Medicine's (ABIM) Maintenance of Certification (MOC) program. Participants will earn MOC points equivalent to the amount of CME credits claimed for the activity. It is the CME activity provider's responsibility to submit participant completion information to ACCME for the purpose of granting ABIM MOC credit.

All other clinicians completing this activity will be issued a certificate of participation. To participate in this journal CME activity: (1) review the learning objectives and author disclosures; (2) study the education content; (3) take the post-test with a $75 \%$ minimum passing score and complete the evaluation at http://www.medscape.org/journal/eid; and (4) view/print certificate. For CME questions, see page 832.

Release date: March 13, 2020; Expiration date: March 13, 2021

\section{Learning Objectives}

Upon completion of this activity, participants will be able to:

- Describe tickborne pathogens in Washington state, according to surveillance data integrating human case histories and detection of pathogens in field-collected ticks

- Determine detection of pathogens in field-collected ticks in Washington state during 2011 to 2016, according to surveillance data

- Identify clinical and public health implications of detection of tickborne pathogens and diseases in Washington state, according to surveillance data

\section{CME Editor}

Deborah Wenger, MBA, Copyeditor, Emerging Infectious Diseases. Disclosure: Deborah Wenger, MBA, has disclosed no relevant financial relationships.

\section{CME Author}

Laurie Barclay, MD, freelance writer and reviewer, Medscape, LLC. Disclosure: Laurie Barclay, MD, has disclosed no relevant financial relationships.

\section{Authors}

Disclosures: Elizabeth A. Dykstra, PhD, MS; Hanna N. Oltean, MPH; David Kangiser, MSc; Nicola Marsden-Haug, MPH; Stephen M. Rich, PhD; Guang Xu, PhD; Min-Kuang Lee, DVM, MSc; Muhammad G. Morshed, PhD; and Rebecca J. Eisen, $\mathbf{P h D}$, have disclosed no relevant financial relationships. Christine B. Graham, MS, has disclosed the following relevant financial relationships: owns stocks, stock options, or bonds from Bio-Rad Laboratories; GlaxoSmithKline; Illumina; Ironwood Pharmaceuticals, Inc.; Johnson and Johnson Pharmaceutical Research \& Development, L.L.C.; Laboratory Corporation of America; Lilly USA, LLC; Medicines and Co.; Medtronic, Inc.; Merck \& Co., Inc.; Quest Diagnostics; Takeda Pharmaceuticals North America, Inc..

Author affiliations: Washington State Department of Health, Olympia, Washington, USA (E.A. Dykstra, H.N. Oltean, D. Kangiser,

N. Marsden-Haug); University of Massachusetts-Amherst, Amherst, Massachusetts, USA (S.M. Rich, G. Xu); British Columbia Centre for Disease Control, Vancouver, British Columbia, Canada (M.-K. Lee,
M.G. Morshed); Centers for Disease Control and Prevention, Fort Collins, Colorado, USA (C.B. Graham, R.J. Eisen)

DOI: https://doi.org/10.3201/eid2604.191382

${ }^{1}$ These authors contributed equally to this article. 
Tickborne diseases are rare in Washington, USA, and the ecology of these pathogens is poorly understood. We integrated surveillance data from humans and ticks to better describe their epidemiology and ecology. During 2011-2016, a total of 202 tickborne disease cases were reported in Washington residents. Of these, 68 (34\%) were autochthonous, including cases of Lyme disease, Rocky Mountain spotted fever, tickborne relapsing fever, and tularemia. During May 2011-December 2016, we collected 977 host-seeking ticks, including Ixodes pacificus, I. angustus, I. spinipalpis, I. auritulus, Dermacentor andersoni, and $D$. variabilis ticks. The prevalence of Borrelia burgdorferi sensu stricto in I. pacificus ticks was $4.0 \%$; of $B$. burgdorferi sensu lato, $3.8 \%$; of $B$. miyamotoi, $4.4 \%$; and of Anaplasma phagocytophilum, 1.9\%. We did not detect Rickettsia rickettsii in either Dermacentor species. Case-patient histories and detection of pathogens in field-collected ticks indicate that several tickborne pathogens are endemic to Washington.

Tickborne infections are the most common cause 1 of vectorborne disease in the United States (1). Disease epidemiology is complex, the result of many causes, such as spatiotemporal variation in infected vectors, human behavior, reservoir host abundance, and climate variation $(1,2)$. Compared with highly endemic areas such as the upper Midwest and northeastern United States, for the state of Washington, the epidemiology and ecology of tickborne diseases is not well characterized. Washington is divided into 39 counties spread across multiple, distinct ecosystems; the diverse ecology presents a range of potential vector habitats.

Human Lyme disease cases, with and without travel outside the state within the exposure period, have been confirmed in Washington (3). Borrelia burgdorferi sensu stricto (s.s.)-infected Ixodes pacificus ticks have been documented in far western North America, including California, USA, and British Columbia, Canada (4-6). In addition, a recent study in Washington documented canine seroprevalence of 3.8 cases /1,000 dogs (7). Anaplasma phagocytophilum has been reported in small mammals $(8,9)$ and in vector ticks in California (10); clinical cases of anaplasmosis have been reported in dogs from California to British Columbia $(7,11,12)$.

Rare cases of autochthonous babesiosis have been reported in Washington, 3 caused by Babesia duncani and 1 caused by a $B$. divergens-like organism (13-15). Evidence of $D$. albipictus ticks as the vector for $B$. duncani has only recently emerged (16).

Three of 11 Ixodes tick species (I. pacificus, I. angustus, and I. spinipalpis) reported from Washington are known or suspected vectors for tickborne diseases
(17). I. pacificus ticks are frequent human-biters, and the species is an established vector of $B$. burgdorferi s.s. and A. phagocytophilum and a putative vector of B. miyamotoi (18). I. angustus ticks can experimentally transmit $B$. burgdorferi s.s. and might play a role in the spirochete's enzootic cycle $(19,20)$; likewise, I. spinipalpis ticks might play a role in the natural maintenance of B. burgdorferi sensu lato (s.1.) (21).

Competent reservoirs for B. burgdorferi s.s., including deer mice (Peromyscus maniculatus), western gray squirrels (Sciurus griseus), and several Tamias spp. chipmunks, are found in Washington (22-25). $P$. maniculatus deer mice have been found infected with B. burgdorferi s.l. in western Washington (22). Although not recognized as human pathogen reservoirs, lizards are notable blood-meal hosts for immature $I$. pacificus ticks $(26,27)$ and 3 lizard species are found in Washington: northern alligator lizard (Elgaria coerulea), southern alligator lizard (E. multicarinata), and the western fence lizard (Sceloporus occidentalis) $(25,28$; C.S. Arnason, Biology of the western black-legged tick, Ixodes pacificus, (Cooley and Kohls, 1943): a potential vector of Lyme disease in south coastal British Columbia [master's thesis], Vancouver: Simon Fraser University; 1992). Both E. multicarinata and S. occidentalis lizards are zooprophylactic against B. burgdorferi.

Autochthonous cases of Rocky Mountain spotted fever (RMSF) were reported in Washington each year until the 1940s (29). To date, there is no published evidence of $R$. rickettsii in ticks collected in Washington. Tularemia is prevalent throughout the Northern Hemisphere and occurs in many animal species (30). Recent Francisella tularensis antibody detections were reported from wildlife in Idaho (31). Up to 10 cases of tularemia are reported each year in Washington (29). $D$. andersoni and D. variabilis ticks, both competent vectors of $R$. rickettsii and F. tularensis, occur in the state $(18,32)$. The brown dog tick, Rhipicephalus sanguineus, a known vector of RMSF in the southwest, is also reportedly present $(33,34)$.

Borrelia hermsii, the causative agent of tickborne relapsing fever (TBRF), occurs in Washington and is vectored by Ornithodoros hermsi, a soft tick (family Argasidae) typically found in rodent nests $(35,36)$. TBRF is the most commonly reported autochthonous tickborne disease in Washington; up to 12 cases are reported annually (29). The first documented evidence of canine infection with $B$. hermsii was reported in a dog with travel to Chelan County, Washington (37). $B$. hermsii-positive O. hermsi ticks have also been documented in Washington (38).

Human cases of Lyme disease, anaplasmosis, ehrlichiosis, babesiosis, spotted fever rickettsioses 
(including RMSF), TBRF, and tularemia are reportable to local health jurisdictions in Washington. However, clinical underrecognition and underreporting of disease are suspected. To clarify the epidemiology of tickborne diseases in Washington, we analyzed locally acquired cases and tick surveillance data. Our objectives were to describe tickborne disease epidemiology among autochthonous human cases in Washington during the study period, as well as Ixodid vectors and pathogen detections in ticks collected in Washington.

\section{Materials and Methods}

\section{Human Case Identification}

Human tickborne disease cases are identified through mandatory, but passive, reporting to local health jurisdictions from Washington healthcare providers and laboratories testing Washington residents. We reviewed all cases of anaplasmosis, ehrlichiosis, Lyme disease, babesiosis, TBRF, RMSF, and tularemia reported during 2011-2016. To ensure comparability over time, we reclassified cases to the Council for State and Territorial Epidemiologists case definitions as of 2017. Confirmed and probable cases were included for each condition. Reclassifications were required for Lyme disease, babesiosis, and tularemia. Local health jurisdictions interviewed cases in the year of report to determine clinical course, travel history, and most likely exposure location. Cases were classified as locally acquired (in-state), out-of-state acquired, or unknown exposure location based on a standardized definition. We evaluated frequency distribution of demographic variables for each condition with locally acquired cases.

\section{Tick Surveillance}

Washington State Department of Health (DOH) staff conducted weekly or biweekly tick drags during March-October at 15 sites in 5 counties in western Washington that were identified as having suitable tick habitat, public access, and relative proximity to $\mathrm{DOH}$ offices, thus allowing frequent monitoring. We sampled 7 sites regularly for $\geq 2$ years and 8 sites for 1 year. Sampling was also performed in 2 counties deemed most likely exposure locations for locally acquired Lyme disease cases reported during 20112016. We conducted surveillance using tick drags, the most effective sampling method for both Ixodes and Dermacentor ticks. Lack of resources and capacity prevented us from including Argasid tick surveillance as part of this study. We sampled by dragging a $1 \mathrm{~m}^{2}$ piece of flannel on the ground along either a $30-\mathrm{m}$ transect or for 30 minutes in a plot created in a specific vegetation type. We inspected drags for ticks every 3-6 meters. We also obtained ticks from partners in 15 counties who found unattached, unfed ticks on themselves and reported GPS collection locations.

Upon collection, we speciated ticks using standard taxonomic keys, then stored them in vials of $95 \%$ ethanol at $4^{\circ} \mathrm{C}(17,39,40)$. We submitted specimens to either the Laboratory of Medical Zoology, University of Massachusetts-Amherst (Amherst, MA, USA); the Centre for Disease Control, British Columbia (Vancouver, BC, Canada); or the US Centers for Disease Control and Prevention (Fort Collins, CO, USA) for pathogen testing.

\section{DNA Extraction and Molecular Identification}

Pathogen testing varied by laboratory and over time; groups of ticks were tested by different laboratories for different pathogens. Testing of Ixodes and Dermacentor ticks followed each laboratory's protocols $(33,41-43)$. Ixodes ticks were tested for A. phagocytophilum, B. burgdorferi s.s. and s.l., B. miyamotoi, B. mayonii, Babesia spp., B. microti, Ehrlichia muris-like agent, Powassan virus, Heartland virus, Colorado tick fever virus, and Bourbon virus. Dermacentor ticks were tested for F. tularensis, R. rickettsii, Powassan virus, Heartland virus, Colorado tick fever virus, and Bourbon virus. B. burgdorferi s.l. detected in ticks tested before 2015 were not subspeciated.

\section{Results}

During 2011-2016, a total of 202 cases of tickborne disease were reported in Washington residents; because of reclassification, this number does not match what is reported in Centers for Disease Control and Prevention notifiable condition data. Of these cases, 68 (34\%) were autochthonous: Lyme disease (16 cases), RMSF ( 2 cases), TBRF ( 25 cases), and tularemia ( 25 cases). Yearly counts of locally acquired tickborne disease cases were low; $<20$ cases were reported annually (Figure 1). Tularemia and TBRF were the most frequently reported autochthonous tickborne diseases. All TBRF exposures were in eastern Washington, most in Okanogan and Spokane counties, whereas tularemia cases were broadly distributed (Figure 2). Low numbers (2-6 cases) of locally acquired Lyme disease were reported each year; for each case, no travel outside Washington during exposure periods was reported. We determined likely exposure locations based on exposure to tick habitat or known tick bite if travel to multiple counties occurred during the exposure period; these cases involved 12 counties in both eastern and western Washington.

Only 2 probable cases of RMSF were reported; both met the minimum IgG detection value. One 


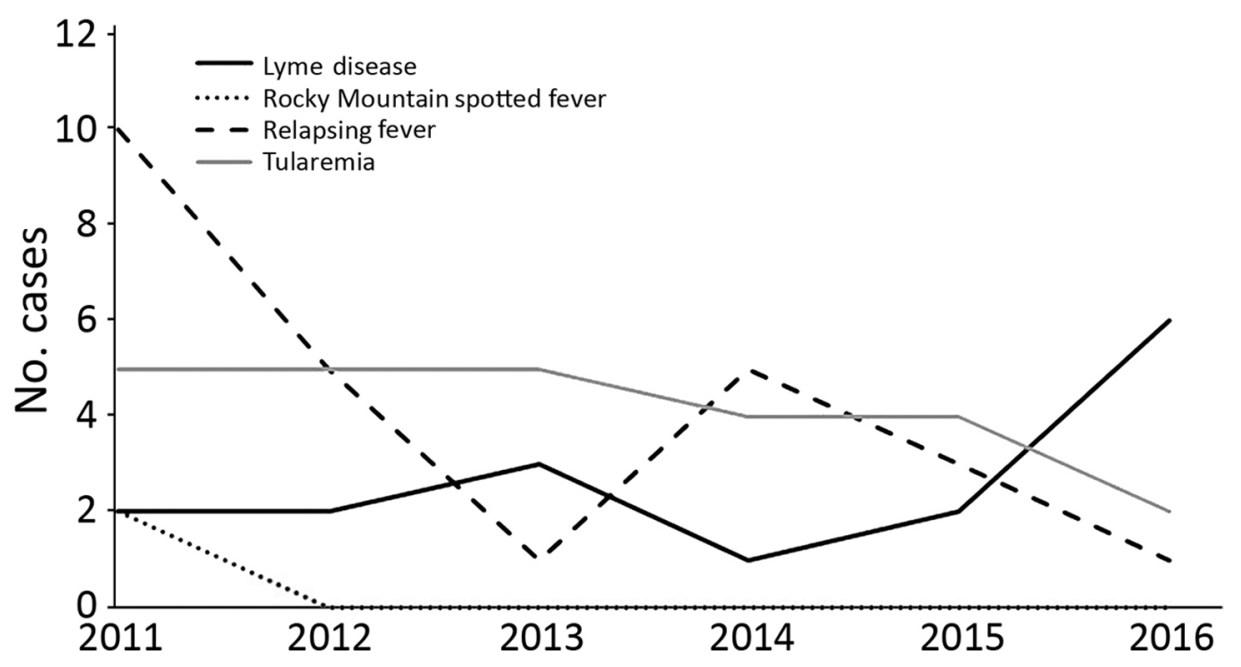

Figure 1. Locally acquired cases of tickborne diseases, Washington, USA, 2011-2016. case-patient experienced fever, lymphadenopathy, and a single ulcerated lesion. The second case-patient reported fever and myalgia with no rash and reported a known tick bite; however, the tick was detected after symptom onset. Both patients reported likely exposure in north central Washington.

Tickborne diseases cases were reported throughout the year; the highest case counts occurred during April-October. Lyme disease cases in May, tularemia cases in July, and TBRF cases in September.
Lyme disease was the most commonly reported imported tickborne disease, and overall case counts of imported Lyme disease increased over the study period (Figure 3). Low numbers of travel-associated anaplasmosis, babesiosis, RMSF, and TBRF were reported. Two cases of blood transfusion-associated babesiosis were reported, 1 in 2014 and 1 in 2015. The blood donors in each case were Washington residents with travel history to babesiosis-endemic states (Massachusetts and Connecticut). No human cases of
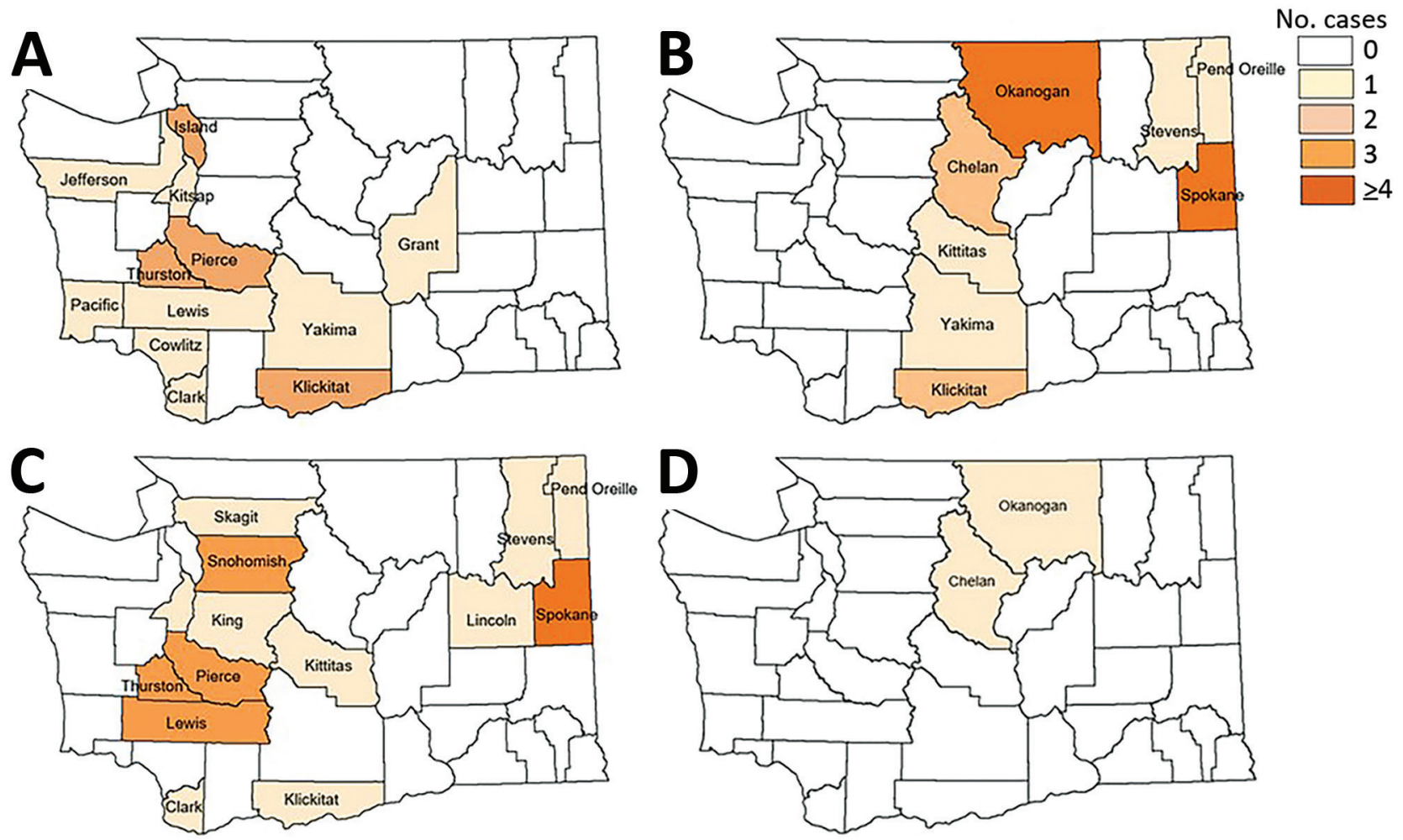

Figure 2. Counties of likely exposure for autochthonous human tickborne disease cases, Washington, USA, 2011-2016. A) Lyme disease; B) tickborne relapsing fever; C) tularemia; D) Rocky Mountain spotted fever. 


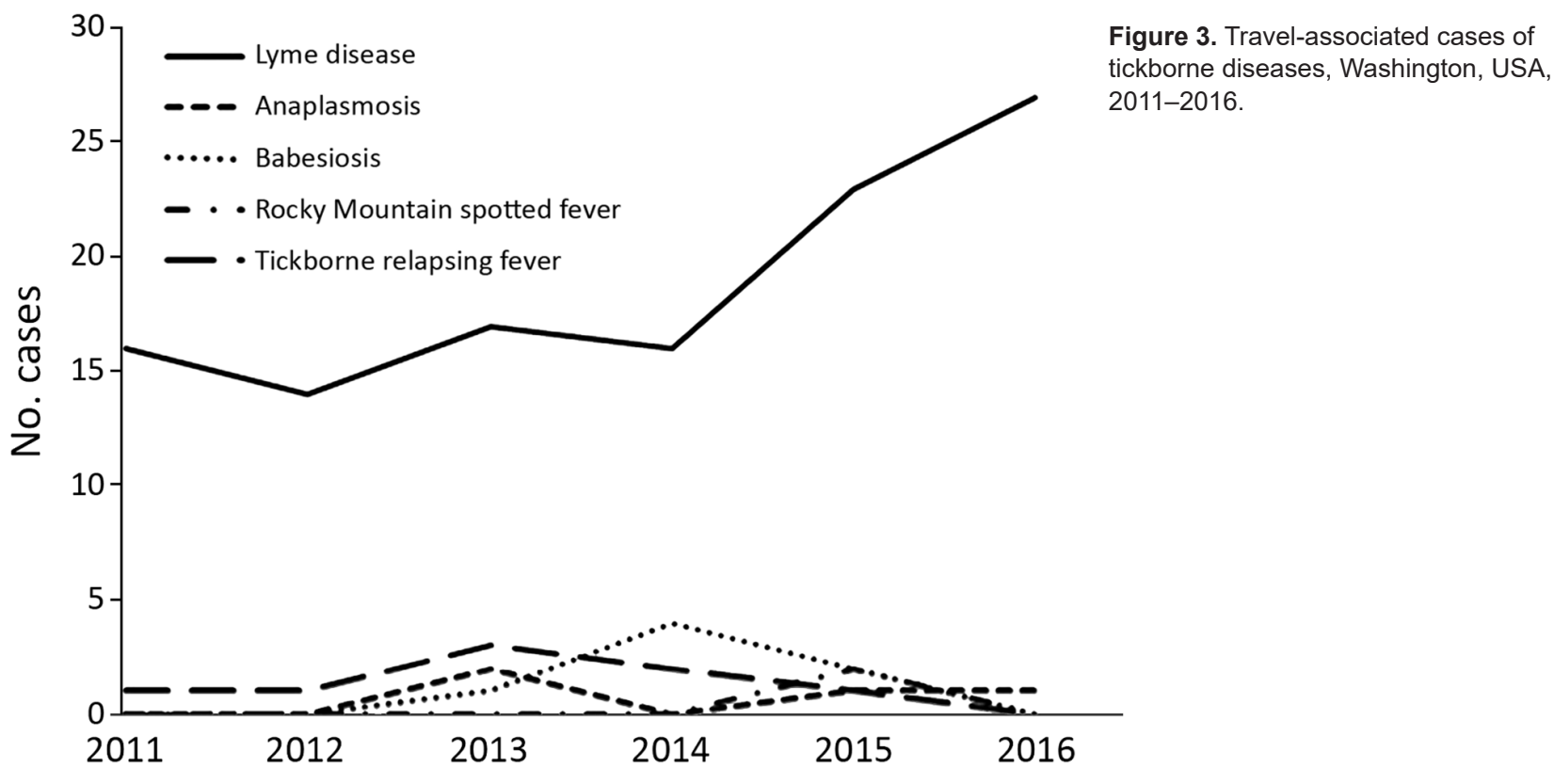

B. miyamotoi infection were reported in Washington residents during this period.

We identified no statistically significant differences in age or gender distribution between casepatients with locally acquired tickborne disease and those with imported cases or unknown exposure history. Among autochthonous cases, $43 \%$ of patients were female and 57\% male; patient ages ranged from 7 to 91 years (median 49 years). Patients with imported cases were $39 \%$ female and $61 \%$ male; ages in this group ranged from 3 to 87 years (median 49 years).

During 2011-2016, we collected 977 unfed, host-seeking ticks from 53 sites in 19 counties (Appendix Tables 1, 2, http://wwwnc.cdc.gov/EID/ article/26/4/19-1382-App1.pdf): I. pacificus $(\mathrm{n}=438)$, I. spinipalpis $(\mathrm{n}=236)$, I. angustus $(\mathrm{n}=99)$, I. auritulus $(\mathrm{n}=5)$, D. andersoni $(\mathrm{n}=151)$, and $D$. variabilis $(\mathrm{n}=46)$. Two Ixodes larvae were unspeciated. The 3 primary vector species, I. pacificus, D. andersoni, and D. variabilis, were active predominantly during the spring; 576/635 (91\%) ticks were collected during MarchMay. Most ticks collected were adults: $100 \%$ D. andersoni and D. variabilis and 96\% (420/438) I. pacificus.
We detected B. burgdorferi s.s. in 14/354 (4.0\%) I. pacificus ticks (Table). However, detections were from only 3 of 5 counties where B. burgdorferi subspeciation was conducted: Clallam, 11/121 (9.1\%); Klickitat, 2/117 (1.7\%); and Yakima, 1/3 (33.3\%) (Figure 4). In addition, we detected $B$. burgdorferi s.l. in 16/421 $(3.8 \%)$ and B. miyamotoi in $10 / 227(4.4 \%)$ I. pacificus ticks and A. phagocytophilum in 5/258 (1.9\%) I. pacificus ticks. Six I. pacificus ticks were co-infected with 2 pathogens: 4 with B. burgdorferi s.s. and B. miyamotoi, 1 with B. burgdorferi s.s. and A. phagocytophilum, and 1 with Borrelia spp. and A. phagocytophilum. We also found A. phagocytophilum in $1 / 234(0.4 \%)$ I. spinipalpis ticks. We detected B. burgdorferi s.l. in 4/235 (1.7\%) I. spinipalpis ticks and in 1/99 (1.0\%) I. angustus ticks. We did not detect $R$. rickettsii or F. tularensis in any field-collected Dermacentor ticks.

\section{Discussion}

Although Washington is considered a low-incidence state for tickborne diseases, our results indicate that vector populations in this state are infected with several disease-causing agents. Tickborne pathogens

\begin{tabular}{|c|c|c|c|c|c|c|c|c|}
\hline \multirow[b]{3}{*}{ Pathogen } & \multicolumn{8}{|c|}{ No. positive/no. tested (\%) } \\
\hline & \multicolumn{2}{|c|}{ I. angustus } & \multicolumn{3}{|c|}{ I. pacificus } & \multicolumn{3}{|c|}{ I. spinipalpis } \\
\hline & Adult & Nymphs & Adult & Nymphs & Larvae & Adults & Nymphs & Larvae \\
\hline Anaplasma phagocytophilum & $0 / 79$ & $0 / 16$ & $5 / 240(2.1)$ & $0 / 17$ & $0 / 1$ & $1 / 4(25.0)$ & $0 / 122$ & $0 / 108$ \\
\hline Borrelia species* & $1 / 82(1.2)$ & $0 / 16$ & $4 / 361(1.1)$ & $0 / 17$ & $0 / 1$ & $1 / 5(20.0)$ & $1 / 122(0.8)$ & $0 / 108$ \\
\hline Borrelia burgdorferi sensu lato & $1 / 83(1.2)$ & $0 / 16$ & $22 / 403(5.5)$ & $0 / 17$ & $0 / 1$ & $1 / 5(20.0)$ & $3 / 122(4.1)$ & $0 / 108$ \\
\hline B. burgdorferi sensu stricto & $0 / 41$ & $0 / 4$ & $14 / 340(4.1)$ & $1 / 14(7.1)$ & $0 / 0$ & $0 / 3$ & $0 / 63$ & $0 / 0$ \\
\hline B. miyamotoi & $0 / 38$ & $0 / 4$ & $10 / 211(4.7)$ & $0 / 16$ & $0 / 0$ & $0 / 2$ & $0 / 67$ & $0 / 0$ \\
\hline
\end{tabular}

${ }^{*}$ Not differentiated to species. 

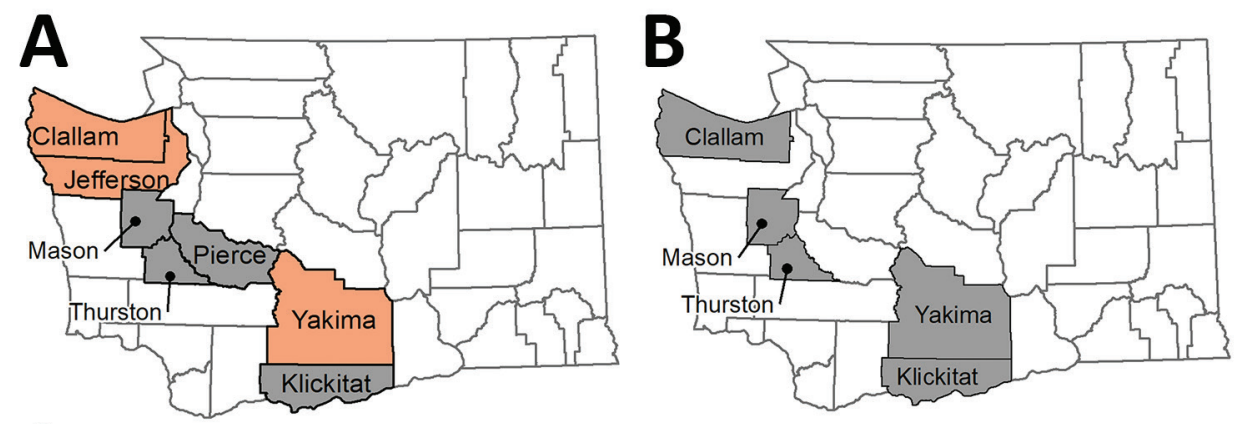

Figure 4. Counties with collection and testing of unfed, field-collected Ixodes pacificus ticks and pathogen detections, Washington, USA, 2011-2016.
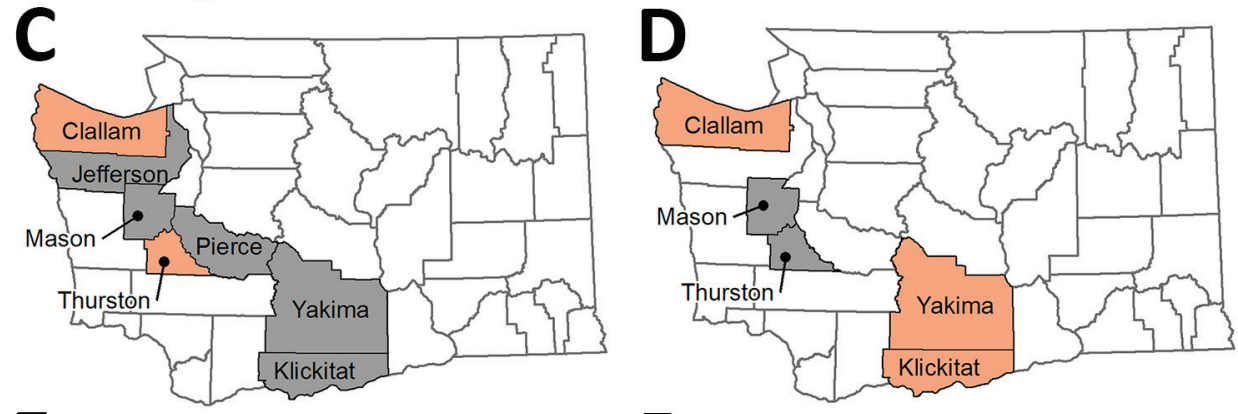

A) Anaplasma phagocytophilum;

B) Borrelia bissettiae;

C) B. burgdorferi sensu lato;

D) B. burgdorferi sensu stricto;

E) B. lanei; F) B. miyamotoi;

G) Borrelia species.
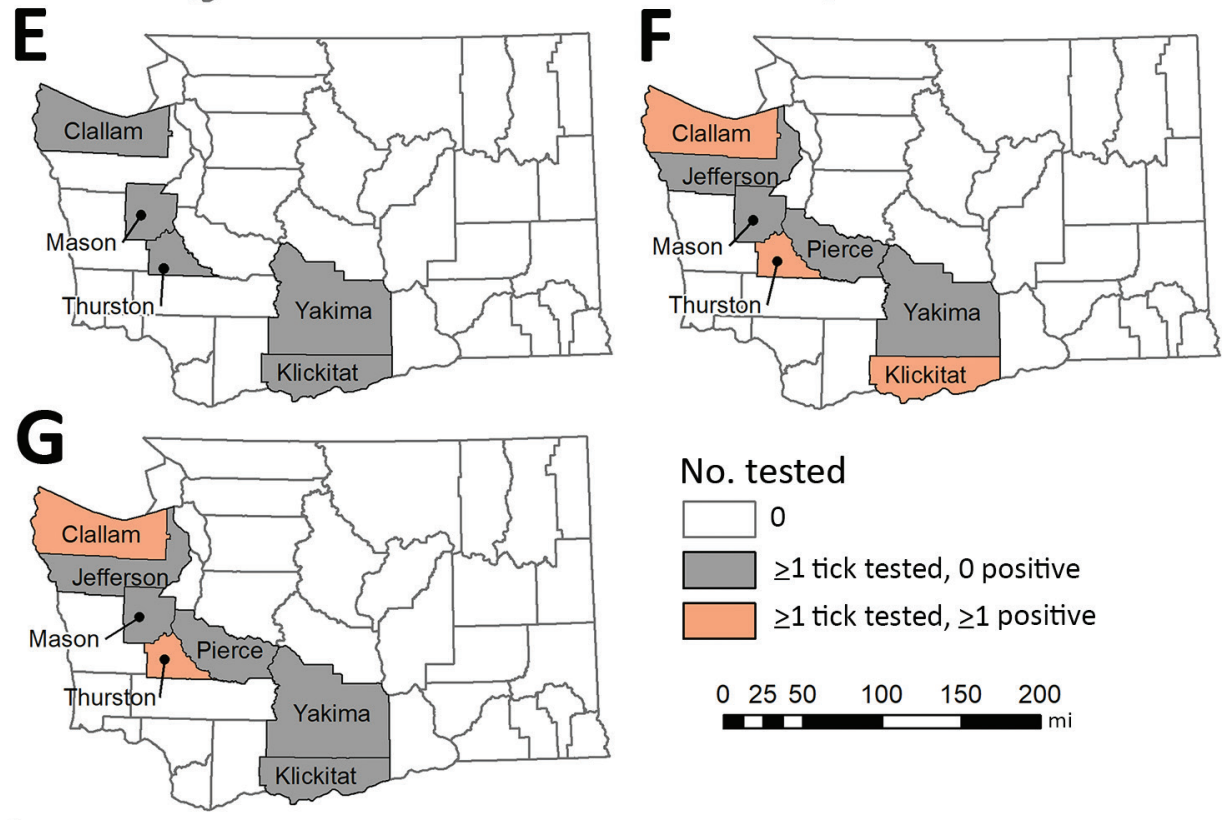

No. tested
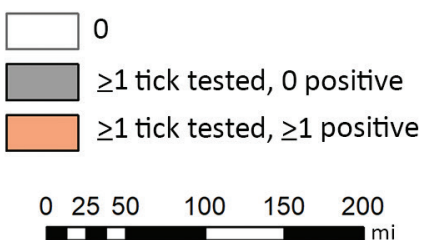

now considered endemic in at least some areas of Washington include B. burgdorferi s.s., B. hermsii, B. miyamotoi, and F. tularensis. Evidence exists for the presence of A. phagocytophilum, B. duncani, and R. rickettsii, but further information is needed to assess risk. Human and animal healthcare providers should be aware of the possible risk of these diseases in their patients and should be vigilant for consistent symptoms paired with exposure histories.

Tick and human surveillance led to a common picture of increased activity in the spring. I. pacificus ticks infected with B. burgdorferi s.s., B. miyamotoi, or A. phagocytophilum were found in 4 of 9 surveyed counties. Human Lyme disease case-patients reported exposures in 12 counties. However, overlap in infected vector populations and human cases of Lyme disease occurred in just 2 counties, Klickitat and Yakima. In the remaining 10 counties, we found no positive detections of B. burgdorferi s.s. Field surveillance was not performed in 7 of these counties (Clark, Cowlitz, Grant, Island, Kitsap, Lewis, and Pacific); in 2 (Jefferson, Pierce), all field-collected I. pacificus tested negative or were not tested; and in 1 (Thurston), $B$. burgdorferi s.l. was detected, but not subspeciated. No autochthonous human cases of anaplasmosis were reported, so there was no overlap with infected vector 
populations. Lack of systematic tick sampling in several of these counties, owing to their distance from $\mathrm{DOH}$ and resource capacity restraints, resulted in few or no unfed ticks collected, thereby limiting pathogen detection. Additional surveillance in these areas is needed to better describe the pathogen prevalence and potential for human-tick encounters.

The higher prevalence of B. burgdorferi s.l. (8.8\%) and B. burgdorferi s.s. (9.1\%) in I. pacificus ticks found in Clallam County suggests that $\geq 1$ competent reservoir host exists in the area. The only zooprophylactic host in the area, the northern alligator lizard $(E$. coerulea), is uncommon at the sites where these ticks were collected, which might be a contributing factor to the higher pathogen prevalence. Alternatively, the small area sampled might be producing unstable prevalence estimates; additional sampling is needed to increase confidence in these findings. No human case-patients with Lyme disease reported exposure in Clallam County, possibly because of limited human-tick interaction in this area; further studies are needed to determine the most likely reservoir and to better describe human-vector interactions. All dually infected I. pacificus ticks also were collected in Clallam County.

In contrast to Clallam County, Klickitat County I. pacificus ticks had much lower prevalence of B. burgdorferi s.s., but 2 human patients with Lyme disease reported exposure there. The hotter, drier habitat of Klickitat County supports populations of all 3 Washington lizard species, which could be a contributing factor to why, despite the abundant tick population, the pathogen prevalence is lower.

The almost total lack of pathogen detection in field-collected I. angustus ticks suggests that this species plays little or no role in the maintenance or transmission of B. burgdorferi in Washington. This finding is confirmed by reports from California, Oregon, and Washington (44). Small numbers of both I. spinipalpis and I. angustus ticks have been found attached to humans in Washington and submitted to $\mathrm{DOH}$ for identification, but their role in pathogen transmission remains unknown.

B. miyamotoi was detected at a similar prevalence in I. pacificus adults as B. burgdorferi s.s., which is contrary to what has been found in other states, where prevalence of $B$. burgdorferi s.s. is often 10 -fold higher than B. miyamotoi (45). No human cases of B. miyamotoi disease have been reported in Washington, which is likely attributable to a lack of clinical suspicion and testing but could also be attributable to I. pacificus ticks being a less efficient vector of $B$. miyamotoi than of B. burgdorferi s.s.
A. phagocytophilum has been reported from dogs, but not humans, in Washington. Strain variation of $A$. phagocytophilum with specific host tropism has been described (46-48); it is unknown whether the strain in Washington is not pathogenic to humans or whether the lack of detection in humans is the result of clinical underrecognition. I. pacificus ticks appear to play a primary role in maintaining this pathogen in nature, although I. spinipalpis ticks might play a minor role.

We detected no Babesia species in any of the ticks tested. A recent study implicating $D$. albipictus ticks as the probable vector of $B$. duncani suggests that the appropriate tick species was not tested.

Further, we found no detections of $R$. rickettsii or F. tularensis in unfed ticks, which is consistent with findings in other states and suggests that both these pathogens are very rare in vector populations. The presence of 2 nonpathogenic strains of Rickettsia, including $R$. peacocki, which is refractory to infection with and maintenance of $R$. rickettsii, suggests that $R$. rickettsii could be present only in focal areas, which is consistent with other findings (49). Very low or zero prevalence of $R$. rickettsii is supported by human case data; only 2 probable cases were reported during the study period. Whereas tularemia is relatively common, the transmission routes for F. tularensis are varied and not limited to tick vectors (50).

Several limitations exist with our study. Field surveillance was conducted at a small number of sites because of limited resources and efforts to determine temporal tick activity. This resulted in inconsistent and largely convenience-based tick surveillance coverage across the state. There remains a paucity of understanding of what specific reservoirs drive the maintenance of these pathogens in nature. However, several known, competent reservoirs for B. burgdorferi s.s. exist in counties where pathogens were detected in the tick population. Little is currently known about the epidemiology of $R$. rickettsii in Washington.

All human case reports described here arose from passive surveillance systems; locally acquired cases required positive laboratory results. Underdiagnosis and underreporting of tickborne disease are likely, as patients might not seek healthcare and healthcare providers might be unaware of the possibility. In addition, common laboratory tests might be negative early in the course of illness and true cases could be missed, particularly if serologic testing is ordered early, rather than nucleic acid detection tests. In contrast, many of the diagnostic tests used for tickborne diseases have poor specificity (e.g., Lyme disease antibody testing) and might crossreact with other species (e.g., Rickettsia testing). The 
application of these tests in a low-incidence setting decreases their positive predictive value, and some of the cases included in this analysis likely represent false-positive results.

The same is likely true for many of the probable Lyme disease cases for which symptoms did not meet the clinical criteria set in the Council for State and Territorial Epidemiologists case definition or for which symptom information was not available. Detections of Lyme disease in 4 counties (Grant, Jefferson, Kitsap, and Lewis) were based on a single probable case each; additional evidence for B. burgdorferi s.s. in ticks in these counties would help lend certainty to these findings. With the exception of Grant County, submissions from veterinarians and the general public indicate that I. pacificus ticks are present in those counties. Similarly, both reported RMSF cases met the minimum cutoff value for IgG; based on clinical histories, these results were likely false-positive. Some misclassification of human case exposure location is probable because there is no way to determine exposure location with certainty. Finally, unknown tickborne disease pathogens could be present in Washington for which diagnostic tests are not available. As awareness of tickborne diseases spreads in the general population and among healthcare providers, we could see an increase in the number of cases as a result of improvements in diagnosis and reporting.

Strengths of this study include tracking tick collection methods and feeding status, which enabled stratification of tick data for analysis of only fieldcollected, unfed ticks. Submissions from host-collected ticks might not represent the true distribution in Washington, instead reflecting the host's travel history and potentially distorting estimates of prevalence. In addition, field surveillance drags were conducted at known sites and, in most cases, at multiple times during the year, providing a better picture of seasonal tick activity. Testing of individual ticks, as opposed to pooling, provided more exact information about pathogen prevalence in each site's tick population and allowed us to assess co-infection rates in individual ticks. All but a very few ticks were identified to species before testing.

We interviewed all human case-patients for exposure history, including travel, enabling us to distinguish travel-related cases from possible autochthonous cases, which is crucial to understanding tickborne disease burden in Washington. The analysis of human and tick data in tandem allowed for a more comprehensive picture of pathogen distributions and prevalence in Washington than analyzing either alone.
The true underlying rate of tickborne diseases in Washington remains unknown. Several human and animal pathogens found in tick populations are endemic to Washington, including $B$. burgdorferi s.s., Babesia spp., F. tularensis, B. hermsii, A. phagocytophilum, B. miyamotoi, and $R$. rickettsii; healthcare providers should be vigilant for symptoms of disease and exposure histories. The rarity of tickborne diseases creates a surveillance and diagnostic challenge; it is difficult to maintain awareness and clinical suspicion for these conditions in lowincidence settings. Surveillance data from fieldcollected ticks identified areas of potential human risk unidentified by existing human surveillance. Ongoing surveillance of both human cases and tick vectors is required to determine the true burden of disease and to improve public health prevention messaging to healthcare providers and the public.

\section{Acknowledgments}

We thank Ashlee-Rose Ferguson, Michelle Jodziewicz, Lauren Sherman, Susan Brush, and Eryn Farkas for their many hours of dedicated tick surveillance; Lillian Manahan for map figures; Kathleen A. Stigi for additional case review and documentation; our tick surveillance partners who supported this project through tick collection and submission; and all the local health jurisdiction and healthcare facility staff who supported this project through patient interviews and specimen collection.

This study was funded by Centers for Disease Control and Prevention Epidemiology and Laboratory Capacity grants.

\section{About the Author}

Dr. Dykstra is the public health entomologist for the Washington State Department of Health, Olympia, Washington, USA. Her research interests include the ecology and epidemiology of vectorborne diseases.

\section{References}

1. Rosenberg R, Lindsey NP, Fischer M, Gregory CJ, Hinckley AF, Mead PS, et al. Vital signs: trends in reported vectorborne disease cases - United States and territories, 2004-2016. MMWR Morb Mortal Wkly Rep. 2018;67:496-501. https://doi.org/10.15585/mmwr.mm6717e1

2. Eisen RJ, Eisen L, Ogden NH, Beard CB. Linkages of weather and climate with Ixodes scapularis and Ixodes pacificus (Acari: Ixodidae), enzootic transmission of Borrelia burgdorferi, and Lyme disease in North America. J Med Entomol. 2016;53:250-61. https://doi.org/10.1093/jme/tjv199

3. Forrester JD, Brett M, Matthias J, Stanek D, Springs CB, Marsden-Haug N, et al. Epidemiology of Lyme disease in low-incidence states. Ticks Tick Borne Dis. 2015;6:721-3. https:/ / doi.org/10.1016/j.ttbdis.2015.06.005 
4. Clover JR, Lane RS. Evidence implicating nymphal Ixodes pacificus (Acari: Ixodidae) in the epidemiology of Lyme disease in California. Am J Trop Med Hyg. 1995;53:237-40. https://doi.org/10.4269/ajtmh.1995.53.237

5. Ogden NH, Lindsay LR, Morshed M, Sockett PN, Artsob H. The emergence of Lyme disease in Canada. CMAJ. 2009;180:1221-4. https://doi.org/10.1503/cmaj.080148

6. Fedorova N, Kleinjan JE, James D, Hui LT, Peeters H, Lane RS. Remarkable diversity of tick or mammalianassociated Borreliae in the metropolitan San Francisco Bay Area, California. Ticks Tick Borne Dis. 2014;5:951-61. https:/ / doi.org/10.1016/j.ttbdis.2014.07.015

7. Carrade D, Foley J, Sullivan M, Foley CW, Sykes JE. Spatial distribution of seroprevalence for Anaplasma phagocytophilum, Borrelia burgdorferi, Ehrlichia canis, and Dirofilaria immitis in dogs in Washington, Oregon, and California. Vet Clin Pathol. 2011;40:293-302. https://doi.org/10.1111/ j.1939-165X.2011.00334.x

8. Foley JE, Nieto NC, Adjemian J, Dabritz H, Brown RN. Anaplasma phagocytophilum infection in small mammal hosts of Ixodes ticks, western United States. Emerg Infect Dis. 2008;14:1147-50. https://doi.org/10.3201/eid1407.071599

9. Straub MH, Roy AN, Martin A, Sholty KE, Stephenson N, Foley JE. Distribution and prevalence of vector-borne diseases in California chipmunks (Tamias spp.). PLoS One. 2017; 12:e0189352. https://doi.org/10.1371/journal.pone.0189352

10. Holden K, Boothby JT, Anand S, Massung RF. Detection of Borrelia burgdorferi, Ehrlichia chaffeensis, and Anaplasma phagocytophilum in ticks (Acari: Ixodidae) from a coastal region of California. J Med Entomol. 2003;40:534-9. https:/ / doi.org/10.1603/0022-2585-40.4.534

11. Lester SJ, Breitschwerdt EB, Collis CD, Hegarty BC. Anaplasma phagocytophilum infection (granulocytic anaplasmosis) in a dog from Vancouver Island. Can Vet J. 2005;46:825-7.

12. Poitout FM, Shinozaki JK, Stockwell PJ, Holland CJ, Shukla SK. Genetic variants of Anaplasma phagocytophilum infecting dogs in western Washington state. J Clin Microbiol. 2005;43:796-801. https://doi.org/10.1128/ JCM.43.2.796-801.2005

13. Quick RE, Herwaldt BL, Thomford JW, Garnett ME, Eberhard ML, Wilson M, et al. Babesiosis in Washington state: a new species of Babesia? Ann Intern Med. 1993;119:284-90. https://doi.org/10.7326/0003-4819-119-4-199308150-00006

14. Herwaldt BL, de Bruyn G, Pieniazek NJ, Homer M, Lofy KH, Slemenda SB, et al. Babesia divergens-like infection, Washington state. Emerg Infect Dis. 2004;10:622-9. https://doi.org/10.3201/eid1004.030377

15. Herwaldt BL, Kjemtrup AM, Conrad PA, Barnes RC, Wilson M, McCarthy MG, et al. Transfusion-transmitted babesiosis in Washington state: first reported case caused by a WA1-type parasite. J Infect Dis. 1997;175:1259-62. https://doi.org/10.1086/593812

16. Swei A, O'Connor KE, Couper LI, Thekkiniath J, Conrad PA, Padgett KA, et al. Evidence for transmission of the zoonotic apicomplexan parasite Babesia duncani by the tick Dermacentor albipictus. Int J Parasitol. 2019;49:95-103. https:/ / doi.org/10.1016/j.ijpara.2018.07.002

17. Keirans JE, Clifford CM. The genus Ixodes in the United States: a scanning electron microscope study and key to the adults. J Med Entomol Suppl. 1978;2(Suppl 2):1-149. https://doi.org/10.1093/jmedent/15.suppl2.1

18. Eisen RJ, Kugeler KJ, Eisen L, Beard CB, Paddock CD. Tick-borne zoonoses in the United States: persistent and emerging threats to human health. ILAR J. 2017;58:319-35. https://doi.org/10.1093/ilar/ilx005
19. Bannerjee SN, Banerjee M, Smith JA, Fernando K. Lyme disease in British Columbia - an update. In: Proceedings of the VII Annual Lyme Disease Foundation International Conference, Stamford, Connecticut, 1994 April 22-23. p. 88.

20. Peavey CA, Lane RS, Damrow T. Vector competence of Ixodes angustus (Acari: Ixodidae) for Borrelia burgdorferi sensu stricto. Exp Appl Acarol. 2000;24:77-84. https:/ / doi.org/10.1023/A:1006331311070

21. Margos G, Lane RS, Fedorova N, Koloczek J, Piesman J, Hojgaard A, et al. Borrelia bissettiae sp. nov. and Borrelia californiensis sp. nov. prevail in diverse enzootic transmission cycles. Int J Syst Evol Microbiol. 2016;66:1447-52. https:// doi.org/10.1099/ijsem.0.000897

22. United States Army. Pest management study/hantavirus survey no. 18-RF-0893-97, Fort Lewis, WA, October 27November 2, 1996. Fort Lewis (WA): US Army; 1997.

23. Salkeld DJ, Leonhard S, Girard YA, Hahn N, Mun J, Padgett KA, et al. Identifying the reservoir hosts of the Lyme disease spirochete Borrelia burgdorferi in California: the role of the western gray squirrel (Sciurus griseus). Am J Trop Med Hyg. 2008;79:535-40. https://doi.org/10.4269/ ajtmh.2008.79.535

24. Foley JE, Nieto NC. The ecology of tick-transmitted infections in the redwood chipmunk (Tamias ochrogenys). Ticks Tick Borne Dis. 2011;2:88-93. https:/ / doi.org/ 10.1016/j.ttbdis.2010.11.003

25. Washington Nature Mapping Program [cited 2019 Jan 11]. http://naturemappingfoundation.org/natmap/maps/wa

26. Lane RS, Quistad GB. Borreliacidal factor in the blood of the western fence lizard (Sceloporus occidentalis). J Parasitol. 1998;84:29-34. https://doi.org/10.2307/3284524

27. Wright SA, Lane RS, Clover JR. Infestation of the southern alligator lizard (Squamata: Anguidae) by Ixodes pacificus (Acari: Ixodidae) and its susceptibility to Borrelia burgdorferi. J Med Entomol. 1998;35:1044-9. https:/ / doi.org/10.1093/ jmedent/35.6.1044

28. Castro MB, Wright SA. Vertebrate hosts of Ixodes pacificus (Acari: Ixodidae) in California. J Vector Ecol. 2007;32: 140-9. https:/ / doi.org/10.3376/1081-1710(2007)32[140: VHOIPA]2.0.CO;2

29. Washington State Department of Health. Communicable disease report 2017 [cited 2019 Jan 11]. https:/ / www.doh. wa.gov/Portals/1/Documents/5100/420-004CDAnnualReport2017.pdf

30. Ellis J, Oyston PCF, Green M, Titball RW. Tularemia. Clin Microbiol Rev. 2002;15:631-46. https:/ / doi.org/ 10.1128/CMR.15.4.631-646.2002

31. National Wildlife Disease Program. The NWDP tularemia update. May 2011:1-4 [cited 2019 Jan 11]. https://www. aphis.usda.gov/wildlife_damage/nwdp/pdf/NWDP\%20 Tularemia\%20Surveillance\%20Update_May\%202011.pdf

32. Yunker CE, Keirans JE, Clifford CM, Easton ER. Dermacentor ticks (Acari: Ixodoidea) of the new world: a scanning electron microscope atlas. Proc Entomol Soc Wash. 1986;88:609-27.

33. Dantas-Torres F. Biology and ecology of the brown dog tick, Rhipicephalus sanguineus. Parasit Vectors. 2010;3:26. https:/ / doi.org/10.1186/1756-3305-3-26

34. Centers for Disease Control and Prevention. Approximate distribution of the brown dog tick [cited 2019 Jan 10]. https://www.cdc.gov/ticks/maps/brown_dog_tick.pdf

35. Burgdorfer W, Mavros AJ. Susceptibility of various species of rodents to the relapsing fever spirochete, Borrelia hermsii. Infect Immun. 1970;2:256-9.

36. Schwan TG, Raffel SJ, Schrumpf ME, Porcella SF. Diversity and distribution of Borrelia hermsii. Emerg Infect Dis. 2007;13:436-42. https:// doi.org/10.3201/eid1303.060958 
37. Kelly AL, Raffel SJ, Fischer RJ, Bellinghausen M, Stevenson C, Schwan TG. First isolation of the relapsing fever spirochete, Borrelia hermsii, from a domestic dog. Ticks Tick Borne Dis. 2014;5:95-9. https://doi.org/10.1016/j.ttbdis.2013.08.005

38. Thompson RS, Burgdorfer W, Russell R, Francis BJ. Outbreak of tick-borne relapsing fever in Spokane County, Washington. JAMA. 1969;210:1045-50. https:// doi.org/10.1001/ jama.1969.03160320027005

39. Brinton EP, Beck DE, Allred DM. Identification of the adults, nymphs and larvae of ticks of the genus Dermacentor Koch (Ixodidae) in the western United States. Brigham Young University Science Bulletin. Biological Series. 1965;5:1-44.

40. Durden LA, Keirans JE. Nymphs of the genus Ixodes (Acari: Ixodidae) of the United States: taxonomy, identification key, distribution, hosts, and medical/veterinary importance. Lanham (MD): Entomological Society of America; 1996.

41. Johnson TL, Graham CB, Boegler KA, Cherry CC, Maes SE, Pilgard MA, et al. Prevalence and diversity of tick-borne pathogens in nymphal Ixodes scapularis (Acari: Ixodidae) in eastern national parks. J Med Entomol. 2017;54:742-51.

42. Graham CB, Maes SE, Hojgaard A, Fleshman AC, Sheldon SW, Eisen RJ. A molecular algorithm to detect and differentiate human pathogens infecting Ixodes scapularis and Ixodes pacificus (Acari: Ixodidae). Ticks Tick Borne Dis. 2018;9:390-403. https://doi.org/10.1016/j.ttbdis.2017.12.005

43. Morshed MG, Lee MK, Man S, Fernando K, Wong Q, Hojgaard A, et al. Surveillance for Borrelia burgdorferi in Ixodes ticks and small rodents in British Columbia. Vector Borne Zoonotic Dis. 2015;15:701-5. https:/ / doi.org/10.1089/ vbz.2015.1854

44. Xu G, Pearson P, Dykstra E, Andrews ES, Rich SM. Humanbiting Ixodes ticks and pathogen prevalence from California, Oregon and Washington. Vector Borne Zoonotic Dis. 2019;19:106-14. https://doi.org/10.1089/vbz.2018.2323

45. Barbour AG, Bunikis J, Travinsky B, Hoen AG, Diuk-Wasser MA, Fish D, et al. Niche partitioning of Borrelia burgdorferi and Borrelia miyamotoi in the same tick vector and mammalian reservoir species. Am J Trop Med Hyg. 2009;81:1120-31. https://doi.org/10.4269/ajtmh.2009.09-0208

46. Foley J, Nieto NC, Madigan J, Sykes J. Possible differential host tropism in Anaplasma phagocytophilum strains in the Western United States. Ann N Y Acad Sci. 2008;1149:94-7. https://doi.org/10.1196/annals.1428.066

47. Stuen S, Granquist EG, Silaghi C. Anaplasma phagocytophilum - a widespread multi-host pathogen with highly adaptive strategies. Frontiers Cell Infect Micro. 2013;3:31. https:/ / doi.org/ 10.3389/fcimb.2013.00031

48. Trost CN, Lindsay LR, Dibernardo A, Chilton NB. Three genetically distinct clades of Anaplasma phagocytophilum in Ixodes scapularis. Ticks Tick Borne Dis. 2018;9:1518-27. https://doi.org/10.1016/j.ttbdis.2018.07.002

49. Burgdorfer W, Hayes SF, Mavros AJ. Nonpathogenic rickettsiae in Dermacentor andersoni: a limiting factor for the distribution of Rickettsia rickettsii. In: Burgdorf $\mathrm{W}$ and Anacker RL, editors. Rickettsiae and rickettisal diseases. New York: Academic Press; 1981. p. 585-594.

50. Kugeler KJ, Mead PS, Janusz AM, Staples JE, Kubota KA, Chalcraft LG, et al. Molecular epidemiology of Francisella tularensis in the United States. Clin Infect Dis. 2009;48:863-70. https://doi.org/10.1086/597261

Address for correspondence: Elizabeth A. Dykstra, Washington State Department of Health, Office of Environmental Public Health Sciences, PO Box 47825, Olympia, WA 98504-7825, USA; email: elizabeth.dykstra@doh.wa.gov

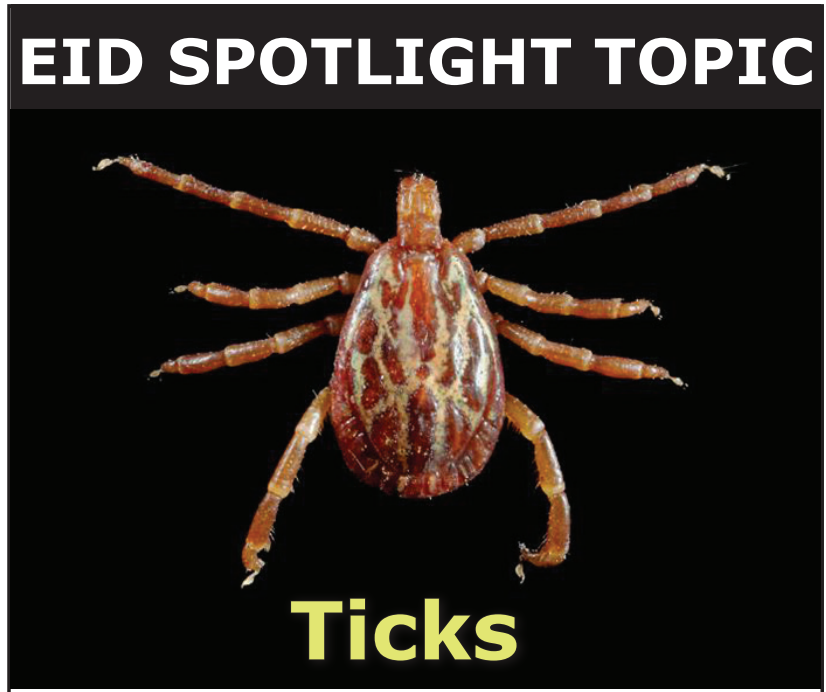

Tens of thousands of cases of tickborne disease are reported each year, including Lyme disease. Lyme disease is the most well-known tickborne disease. However, other tickborne illnesses such as Rocky Mountain spotted fever, tularemia, babesiosis, and ehrlichiosis also contribute to severe morbidity and more mortality each year.
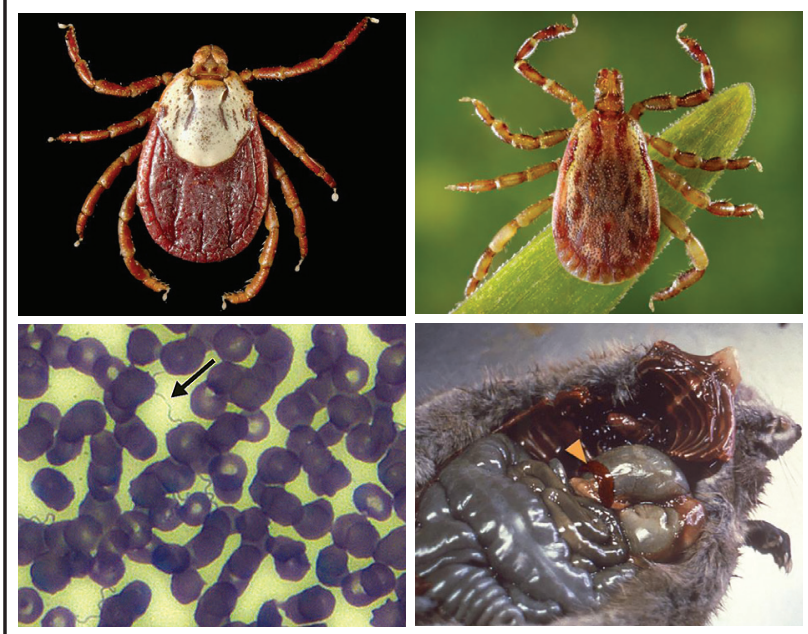

\section{https://wwwnc.cdc.gov/eid/ page/tick-spotlight}

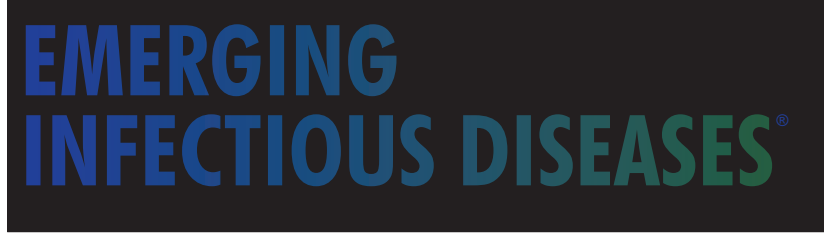

